\title{
Investigation of the soil structure of the area between Yedikule to Sirkeci (İstanbul) using PS logging and earthquake data
}

Ayhan Keskinsezer ${ }^{1}$, Günay Beyhan ${ }^{1}$, and Javid Gallajov ${ }^{1}$

Received 15 February 2019; accepted 25 March 2019; published 8 August 2019.

Marmara Region is located in northwestern Turkey, and the average elevation is of the least. Despite the small size of the region population, its density is above the average of Turkey. The North Anatolian Fault Zone (NAFZ) passing through this region is a fracture that can be observed clearly in its structural characteristics. This region is one of the very active regions in terms of seismic activity when viewed in the historical process. For this reason, earthquake risk analysis is very important for urban planning, construction and major engineering projects such as İstanbul Metro. This engineering project, which has a worldwide design, has a length of $76 \mathrm{~km}$. Not only it connects Asia and Europe with railways, but also provides urban transportation in a fast and convenient way. In this study, the part of the İstanbul Metro between Yedikule and Sirkeci on the European continent is investigated. Numerous boreholes were opened in this project line, but here 7 of the best representatives of the region were selected and examined in this study. These boreholes have a depth of about $60 \mathrm{~m}$ and have penetrated many geological layers and formations in this region. In this study, we used average velocities of $\mathrm{P}$ and $\mathrm{S}$ waves in layers, density, and thickness and formation data based on the PS logs in selected 7 boreholes of Yedikule-Sirkeci line. The influences of linearity on the site response analysis have been detected and evaluated with numerical examples. The earthquake data needful for the Equivalent Linear Earthquake Site Response Analyses computer program solution is the Kocaeli earthquake data on 17 August 1999, which was recorded at the earthquake station in Beşiktaş-İstanbul. In addition to Kocaeli earthquake data, the soil parameters from the boreholes are also transferred and calculated. Thus, important ground features of the area where the engineering structure with huge dimensions are to be constructed have been determined. KEYWORDS: PS logging; İstanbul Metro; Site Response Analysis.

Citation: Keskinsezer, Ayhan, Günay Beyhan, and Javid Gallajov (2019), Investigation of the soil structure of the area between Yedikule to Sirkeci (İstanbul) using PS logging and earthquake data, Russ. J. Earth. Sci., 19, ES4004, doi:10.2205/2019ES000668.

\section{Introduction}

\footnotetext{
${ }^{1}$ Engineering Faculty, Dep. of Geophysical Eng., Sakarya University, Serdivan-Sakarya, Turkey

Copyright 2019 by the Geophysical Center RAS. http://rjes.wdcb.ru/doi/2019ES000668-res.html
}

In the coming years, the possibility of a major earthquake in and around İstanbul is increasing day by day. For this reason, there is a high probability that strong ground movements will occur with destructive effects for historical monuments. İstanbul 
Metro in Bosphorus is one of the large and complex engineering constructions with a tunnel system and railway connections where many stations are located.

Site response analysis has been usually the first step of any seismic soil study. Geoscience engineers have been trying to find both practical and optimal solution techniques for ground reaction analysis under earthquake loads. For this purpose, a two-layered model is assumed for the study area, the upper part of which is soil and the lower part is bedrock. The amplification spectrum of the soils has been computed between the top and the bottom of this ground deposit. Geoscience engineers deal with the effects of earthquakes on humans and surroundings and try to find most appropriate methods to reduce the magnitude of earthquake concerned hazards. The acceleration spectrums have been obtained from records in earthquake stations. The seismic waves radiate from the focus of the earthquake, they take the physical characteristics of the geological layers they meet and head towards the Earth's surface.

Due to the complexity of the nonlinear mechanism, the dynamic behavior of the ground on strong ground shaking has not been quantitatively assessed based on observed ground motion records. Computation methods advanced for the dynamic analysis of grounds are generally defined as one, $2 \mathrm{D}$ or $3 \mathrm{D}$, depending on the need for the problem to be solved. Since 2D or 3D geometry of layers in the soil sections is required for $2 \mathrm{D}$ and $3 \mathrm{D}$ analysis, the 1D approach has been generally preferred. 1D Equivalent linear modeling has been the most commonly used approach in earth science engineering; it assumes that the layers extend horizontally and that the event signal at the base of the deposits has a vertical shear.

Theoretically, surface elevation from the ground indicates an increase in amplitudes of seismic waves as they pass through the soft soil layers on the Earth's surface. The increase has been due to the lower impedance of the ground layers near the surface where the impedance is defined as the product of mass density of soil and wave propagation velocity. In fact, the elevation in the ground is used to represent any difference in ground motion between two nearby places, regardless of whether these differences are due to impedance contrasts. Other elements that can also reduce the differences in ground movements of the two nearby zones include wave-guiding, break-pointing, basin geometry and topography.

One of the fundamental problems that geoscience engineers have to solve in areas where earthquake hazards are present is the estimation of the specific dynamic response of the earth below ground motion. This solution allows engineers to evaluate the degree of liquefaction, conduct the initial analytical phase of seismic stability assessments for slopes and saddles, and evaluate ground motion amplification.

The acceleration time histories thus provided together with the complete definition of the dynamic characteristics of the soils determined from seismic studies are used to understand the answers of the soil columns to earthquake waves. Understanding the response of geological materials under seismic loading to the site is an important element when the building project design model.

The equivalent linear model has been one of the most commonly used approaches in modeling the ground linearity. The fact that the soil is nonlinearity can significantly affect the seismic response of the soil [ Beyhan et al., 2016; Biondi et al., 2014; Campione et al., 2013 and therefore must be determined with caution. By approximating the actual nonlinear, inelastic response of soil, an equivalent linear approach was suggested by Schnabel et al. 1972. Thus, the responses of soils to a seismic signal or earthquake waves recording can be modeled by various mathematical data processing techniques. For this purpose, many algorithms and professional programs have been developed for engineering applications. Shake, ProShake and EERA are examples of related algorithms. The most important reasons for choosing EERA algorithm are; free, easy to use and reliable results. Moreover, the results obtained from the analysis of the data are excellent. During the analysis of the Shake program and EERA programs, the relative acceleration difference occurs in the ground response analysis, especially in periods of 2 to 10 seconds. In this case, the Shake program produces greater impulses and gives erroneous results.

In the equivalent linear approach, linear analyses are performed with ground properties that are iteratively regulated to be steady with an effective level of shear strain induced in the ground. Yoshida 1994, Huang et al. 2001 and Yoshida and Iai 
1998 showed that equivalent linear analysis shows larger peak acceleration, because this method calculates the acceleration over a wide high frequency range.

Numerical studies have been directed using strong-motion array data after 1970s. A few methods have been offered for interpreting site effects by using ground motion data, such as soil to rock spectral ratios. It is very significant to investigate the effect of these parameters on site response analysis in order to make confident assessments of earthquake ground motions at ground locations. Seed and Idriss 1970, Joyner and Chen 1975 and Hwang and Lee 1991 examined the effects of site parameters such as secant shear modulus, low-strain damping ratio, kinds of sand and clay, ground of water table, and depth of bedrock. The studies have shown that the secant shear modulus has a significant effect on the depth of the bedrock or on the results of field response analysis of sand and clay types. The important factors which affect soil amplification include the dynamic characteristics such as thickness, bedrock depth and types of ground sheets on bedrock, shear modulus and damping ratio, and regional effects such as change of these characteristics by depth and deformation, lateral irregularities of ground sheets. In order to investigate the effect of nonlinear analysis on field response analysis, a nonlinear analysis was developed and compared with equivalent linear analysis method. It has been shown that the effect of nonlinear ground conduct is one of the main factors in the response spectrum. Thus, the maximum acceleration distribution along the depth and spectral ratios has shown that equivalent linear analysis gives greater peak acceleration.

The soils have a non-linear behavior during the earthquake. Therefore, it is very difficult to obtain acceptable estimates for the response of soils. In previous studies, earthquakes ground movements in soft ground areas were found to be larger than nearby rock outcrops, depending on local ground conditions. So, Equivalent Linear Earthquake Site Response Analyses program has been used to perform 1D site response analyzes [ Bardet et al., 2000.

\section{The Basic of Equivalent Linear Site Response Analysis Method}

The Equivalent Linear Site Response Analysis program is used for earthquake response analy- sis and includes the Kelvin-Voigt model. In this model, the ground is regarded as a spring, and the strata are assumed to behave as shock absorbers that absorb the earthquake waves. The shear stress $\tau$, the shape changes $\gamma$ and the shape depending on the strain rate $\gamma^{1}$ :

$$
\tau=G \gamma+\eta \gamma
$$

where $G$ is the shear modulus, $\eta$ is the viscosity. The shear stress and velocity are related to the horizontal distance $z$ and the time $t$ index:

$$
\gamma=\frac{\partial u(z, t)}{\partial z}, \quad \dot{\gamma}=\frac{\partial \gamma(z, t)}{\partial t}=\frac{\partial^{2} u(z, t)}{\partial z \partial t}
$$

The analysis here is made by assuming that the shear deformation of the ground layers will occur. In a moving elastic material, the increase in shear stresses will cause these forces to increase in the opposite direction. In order to express this situation mathematically, a differential motion equation has been established and the displacement function has been expressed. The transfer function between the two layers is expressed as the ratio of displacements relative to each other. This data obtained in the time domain is transferred to the frequency domain by Fourier Transform. This transformation is multiplied by the transfer function to obtain the Fourier transform. When the soil behavior calculation is made, elastic analysis should be performed for the whole earthquake period. Deformation calculations must be done efficiently for each layer in the initial calculations. For this, the coefficient which varies depending on the magnitude of the earthquake expressed in $R \gamma$, is found by multiplying by the maximum deformation value.

\section{Geology and Tectonics of Study Area}

The geology of the study area be composed of Trakya formation of the Paleozoic age is represented by siltstone, sandstone and claystone alterations and Cenozoic aged formations the basement. Discordantly overlying Miocene age sediments are differentiated as the Çukurçeşme, Güngören, and Bakırköy formations and constitute clastics, finegrained and precipitated deposits, respectively, indicate fluvial-to-lacustrine depositional surroundings. The alluvium deposits are extended to creek 
beds and stream valleys extending in the North and South direction. In this region, a number of excavations were made and 107 boreholes were opened within the scope of [STFA, 2005]. In addition, all the information gathered and the geological structure of the environment in the light of the finds were revealed (Figure 1). The boundary of the Quaternary and Miocene sediments a dark grayblack clay deposit, the Quaternary sediments are located above the present sea level.

The geological studies show that Neogene age deposits outcrop in the area which include a sequence of strata discordance overlying the Lower Carboniferous age greywacke of Trakya formation and Eocene age limestones of Kirklareli formation. The Neogene sequence, sedimentation of which started transgressive in Late Oligocene, is composed of from bottom to top, gravel and conglomerate, layered sand and clay, and in the upper belt, due to a fluvial environment getting shallower at the end of the Miocene age, sand, clay, marl and limestone layered with clay of Bakırköy formation as an interruption sequence. Figure 1 shows the depth, geological structure and geographical locations of the drillings opened in the region within the scope of İstanbul Metro.

The lithology forming the Bakırköy formation are not only low-strength limestone and marls. The site has wide outcrops of marl or limestone bedded and transitional with clay, belonging to this formation, which is $20-30 \mathrm{~m}$ thickness. In fact, the intermediate layer is sand, clay, marl and limestone. The underlying Gürpınar formation, over time, is covered with sand layers, and the clays; at the end of the faulting is only the northeastern border and a small area outcrop. The Gürpınar formation has been $45-61 \mathrm{~m}$ thick towards the northern end of the site, and the data obtained from the boreholes up to $250 \mathrm{~m}$ deep confirms that the formation is thicker towards the south and southwest and reaches a thickness of $200 \mathrm{~m}$.

The excavations in the region are usually carried out in the Thrace and Güngören formations. Thrace formation consists of sandstone, siltstone, claystone and shale units, rarely found in limestones and pebbles, Güngören formation included clay and marl layer. Also, Çukurçeşme formation consist of loose gravel, sand, silt and Bakırköy formation consist of limestone, shale and marl and many faults and geologic discontinuities in the study area.
The Marmara region has a very active tectonic structure and NAFZ in this region passes through the Sea of Marmara in the direction of E-W. The NAFZ is generally known to have generated large earthquakes $(M>7)$ at 150-year intervals. In 1999 Düzce and Kocaeli earthquakes, the lateral offset along the fault locally exceeded $5 \mathrm{~m}$. The Istanbul district is a block bounded by the Black Sea Basin in the north and the NAFZ in the south border.

\section{Geotechnical Properties of the Area Between Yedikule to Sirkeci}

Measured data from selected 7 boreholes were evaluated to reveal the dynamic characteristic specifications of the soil in the study area. The soil classes in the upper approximately $31 \mathrm{~m}$ are silty sand, sand and variable plasticity owner clays. The soil of the study area are silt, clayey sand, sandy gravel, gravel and clays. The boreholes B-1, B-2 and B-3 are comprised from sand, clay and gravel mixtures. The boreholes B-4, B-5, B-6 and B-7 after deep the $30 \mathrm{~m}$ are composed form mudstone, claystone and sandstone (Figure 1).

\section{The Applications of the Between Yedikule to Sirkeci}

When Turkey's largest city Istanbul's historical periods examined are understood to be the scene of great earthquakes. In the years 509, 1719, 1766 and 1894, there were four large earthquakes in the vicinity of the Marmara Sea, over $M \geq 7$ in size. These earthquakes have greatly affected Istanbul. In the Kocaeli earthquake that took place in 1999, some of the districts were partially affected. In the near future, in connection with the NAFZ, the possibility of a major earthquake in and around Istanbul is increasing day by day. In this direction, Ansal et al. 2009 made a comprehensive deterministic approach to the earthquake hazard in İstanbul city. Furthermore, the scenario earthquakes were computed by deterministic seismic hazard analysis integrated with time-dependent probabilistic hazard evaluations by Spence et al. 2005 and Erdik et al. 2005.

The computer program used in this study is in spreadsheet format and has the ability to include 


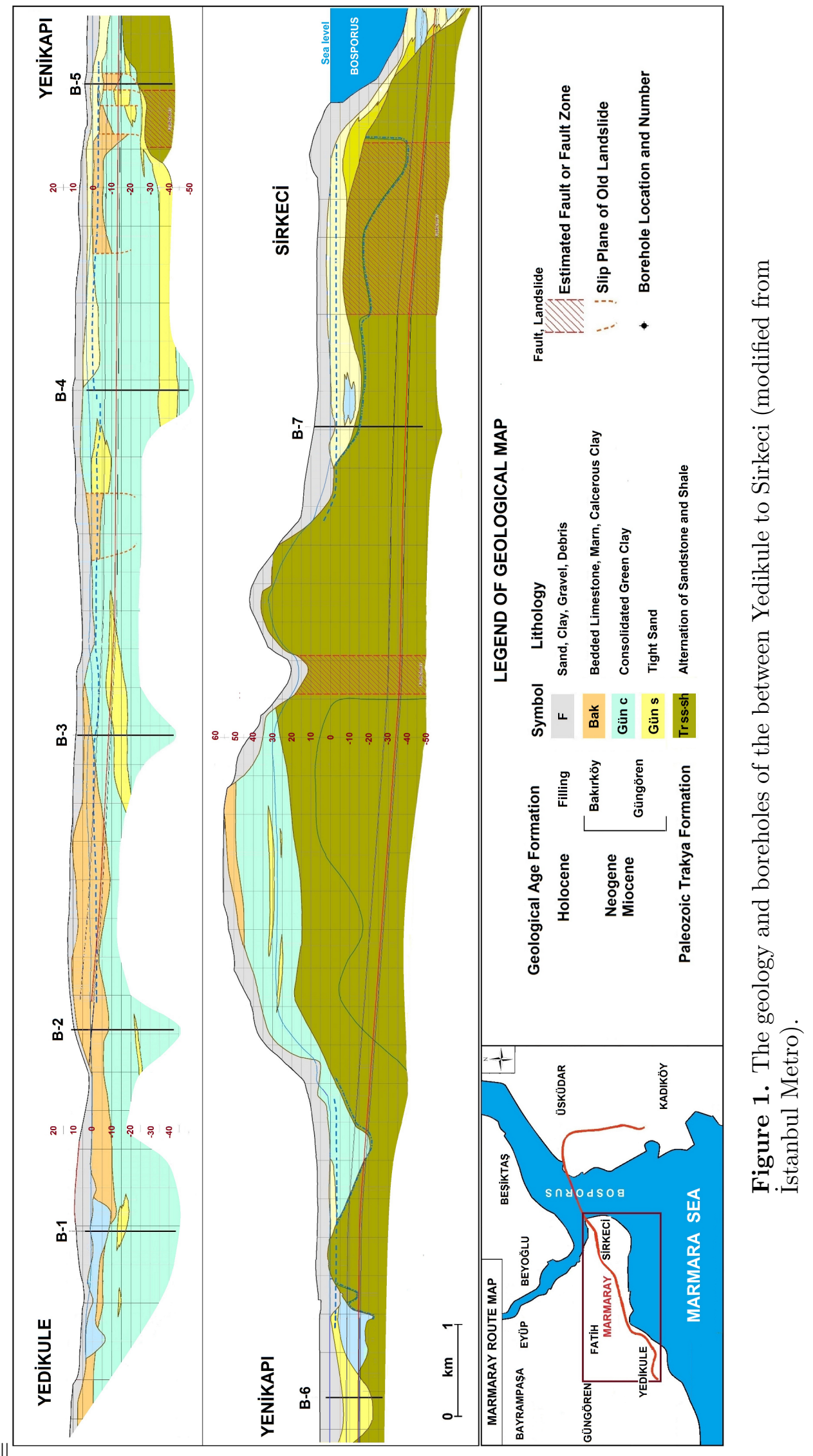




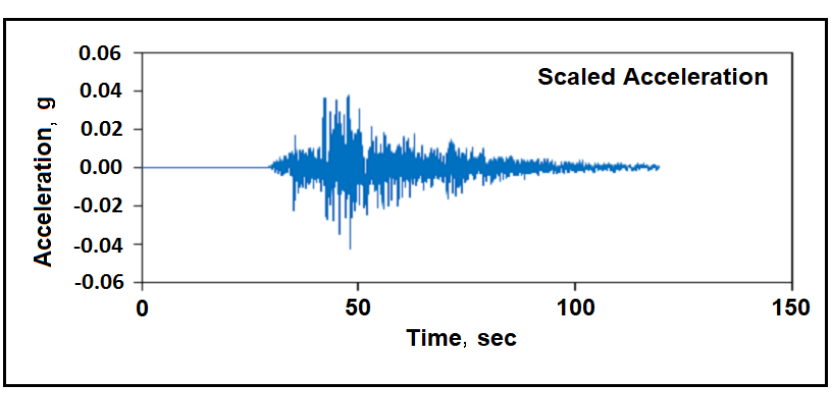

Figure 2. The accelerograph of horizontal component of Kocaeli earthquake (1999) record.

unlimited dynamic soil models in soil response calculations by $1 \mathrm{D}$ linear equivalent method. This program works with earthquake acceleration record and boreholes data. An acceleration record showing the ground properties of the zone was selected for use in calculations in the computer program. The earthquake record used in this study is a the ground motion record of the Kocaeli earthquake of $1999(M w=7.5)$ and has a PGA of $0.04287 \mathrm{~g}$ (Figure 2). This recording point called as BeşiktaşIstanbul station.

A damped linear elastic model and equivalent linear analyses are used to represent the nonlinear conduct of the ground layers. The stressstrain characteristics of the grounds are expressed by use of the correlations declaratory the change of shear module and damping with the shear strain level. For this reason, the average shear requires a database to calculate wave velocities. This database is derived from the values measured from the borehole data.

In this study, PS measurements were taken at 7 different boreholes ranging from 0 to $65 \mathrm{~m}$. The speeds of $V_{p}$ and $V_{s}$ in program, which are transmitted as speed parameters to computer program input, are given in Figure 3 as a comparative graph.

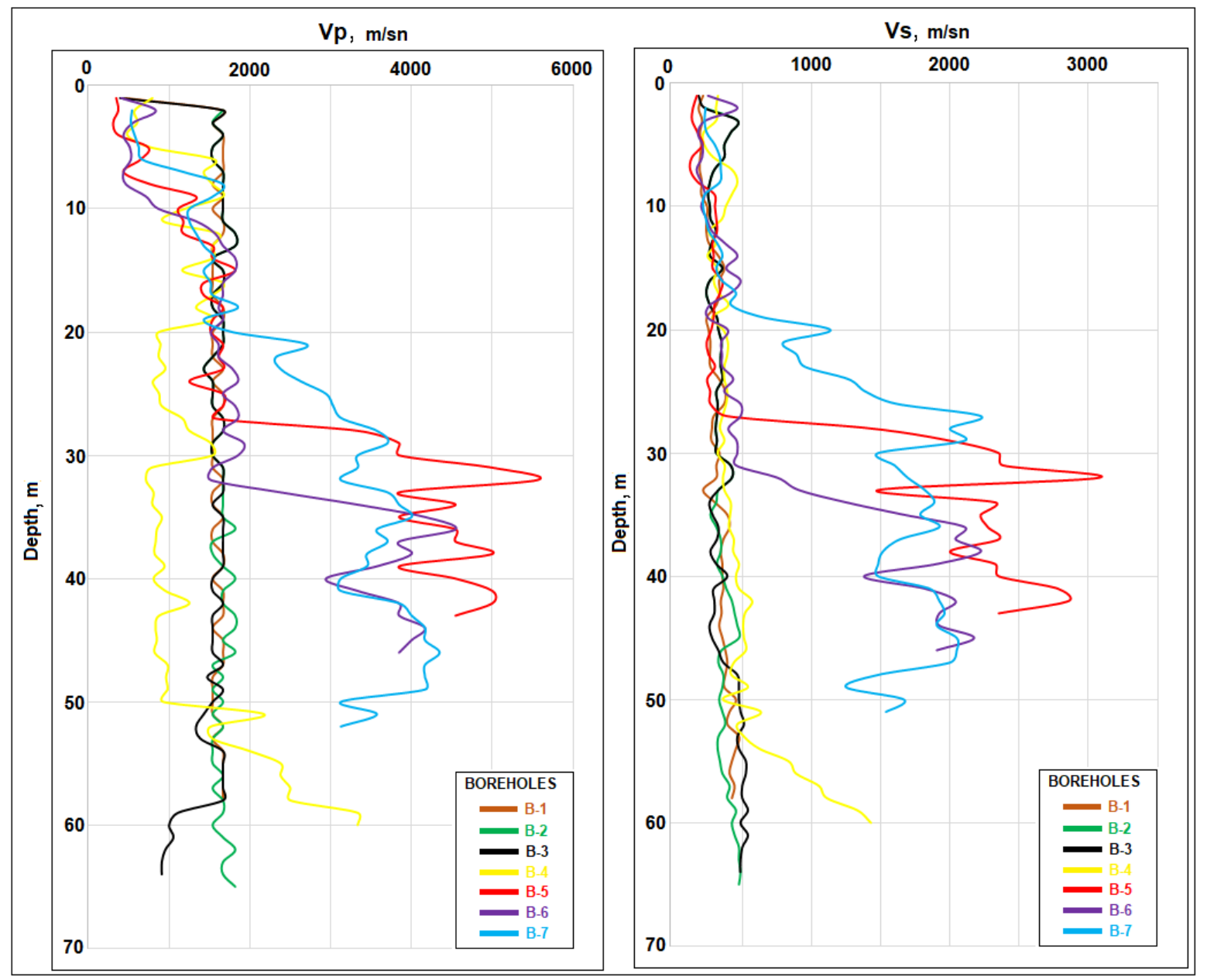

Figure 3. Comparative representation of velocities obtained from PS logging for all boreholes, a) $V_{p}$ values, b) $V_{s}$ values. 


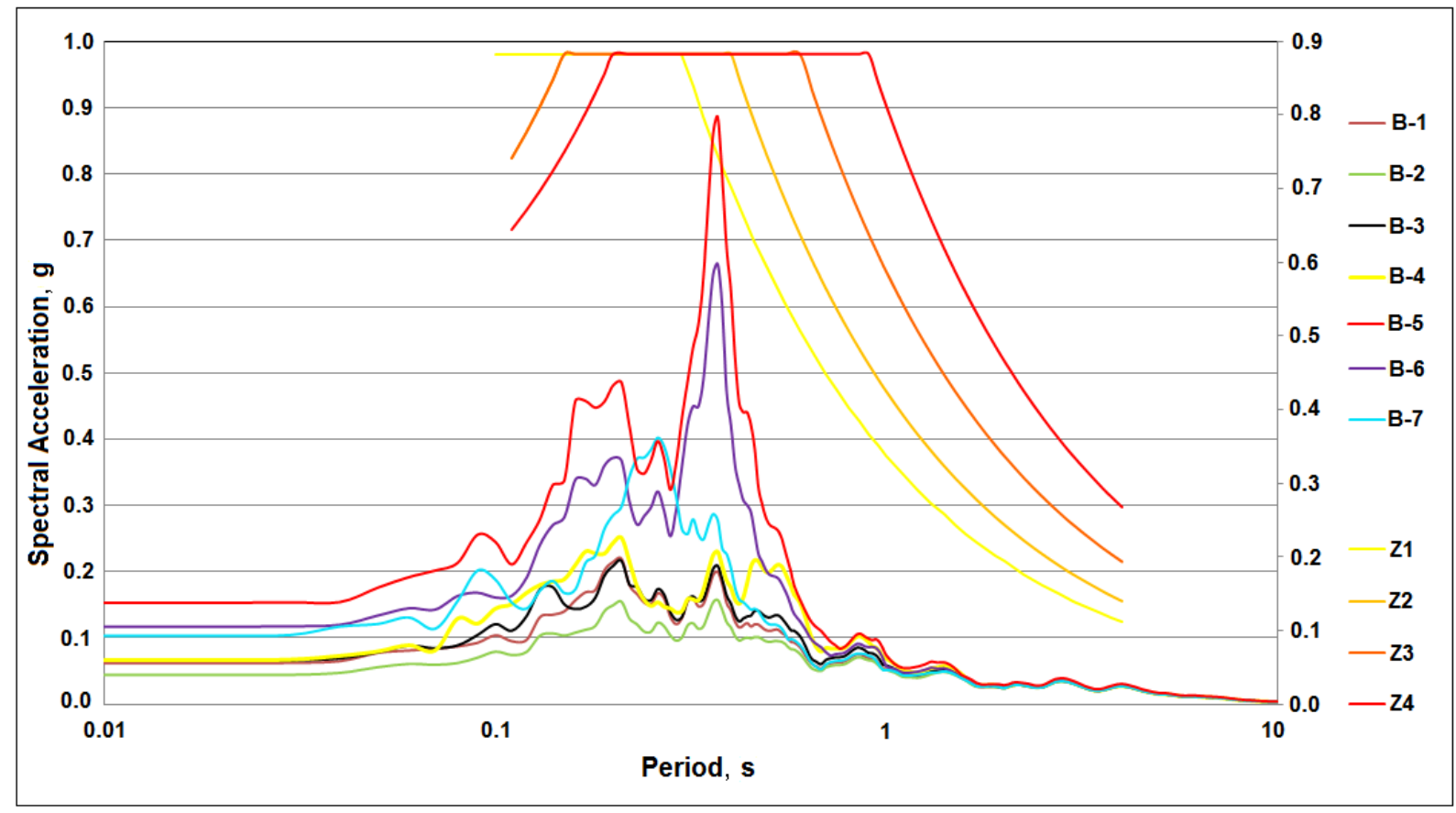

Figure 4. Surface spectral acceleration-period relationships belonging of selected boreholes the in study area and comparison of the Kocaeli earthquake (1999) elastic behavior acceleration spectrums with Turkish Earthquake Regulation Spectrums (2007 elastic medium).

The differences in seismic velocity values due to the geological structure of the environment are clearly observed.

Input data is applied on every off the ground profiles by the computer program to obtain the site responses, and the resulting database occurred of dynamic ground behavior, bearing spectral acceleration-time variation as well as its maximum. Seven exemplary surface spectral accelerationperiod variations from 7 different boreholes are calculated in this study (Figure 4). Pending past earthquakes, the ground motions on soft ground sites were found to be usually larger than those of nearby rock outcrops, count on local ground circumstances.

\section{Modeling of Soil Properties}

Generalized soil profiles were established from the boreholes B-1, B-2, B-3 B-4, B-5, B-6 and B-7. These are located along the İstanbul Metro line and are alluvium soil structures. As calculated using program, the maximum shear stress increases with depth and the maximum shear stresses in boreholes B-4, B-5, B- 6 and B-7 are in the range of $26 \mathrm{kPa}-$ $49 \mathrm{kPa}$, also boreholes B-1, B-2 and B-3 with maximum shear stresses range of $15 \mathrm{kPa}-21 \mathrm{kPa}$ can be classified as being low acceleration (Figure 5 a, Figure 5b).

Decrease of the $\mathrm{S}$ wave velocity in the deep layers can be seen in all of the boreholes (Figure 6) while the acceleration values decreased in an irregular style (Figure 5b), indicating that the soil is heterogeneous by means of material and structural. This method has been applied since the thicknesses and specifications of the layers changed from surface to end in the boreholes.

It can be stressed that the alluvial region soils particularly under Yenikapı and environs the lowest shear wave velocities between $0-100 \mathrm{~m} / \mathrm{s}$ has been shown Figure 5a. The shear wave velocity (VS30) variation of the grounds given in Figure 7 brighten the cause of the low strength of the soils in the area, which is ascendency of these soils. Shear wave velocities of upper $66 \mathrm{~m}$ has been measured between $195-520 \mathrm{~m} / \mathrm{s}$ in the boreholes B-1, B-2 and borehole B-3.

The shear modulus for layers deeper than 36 me- 


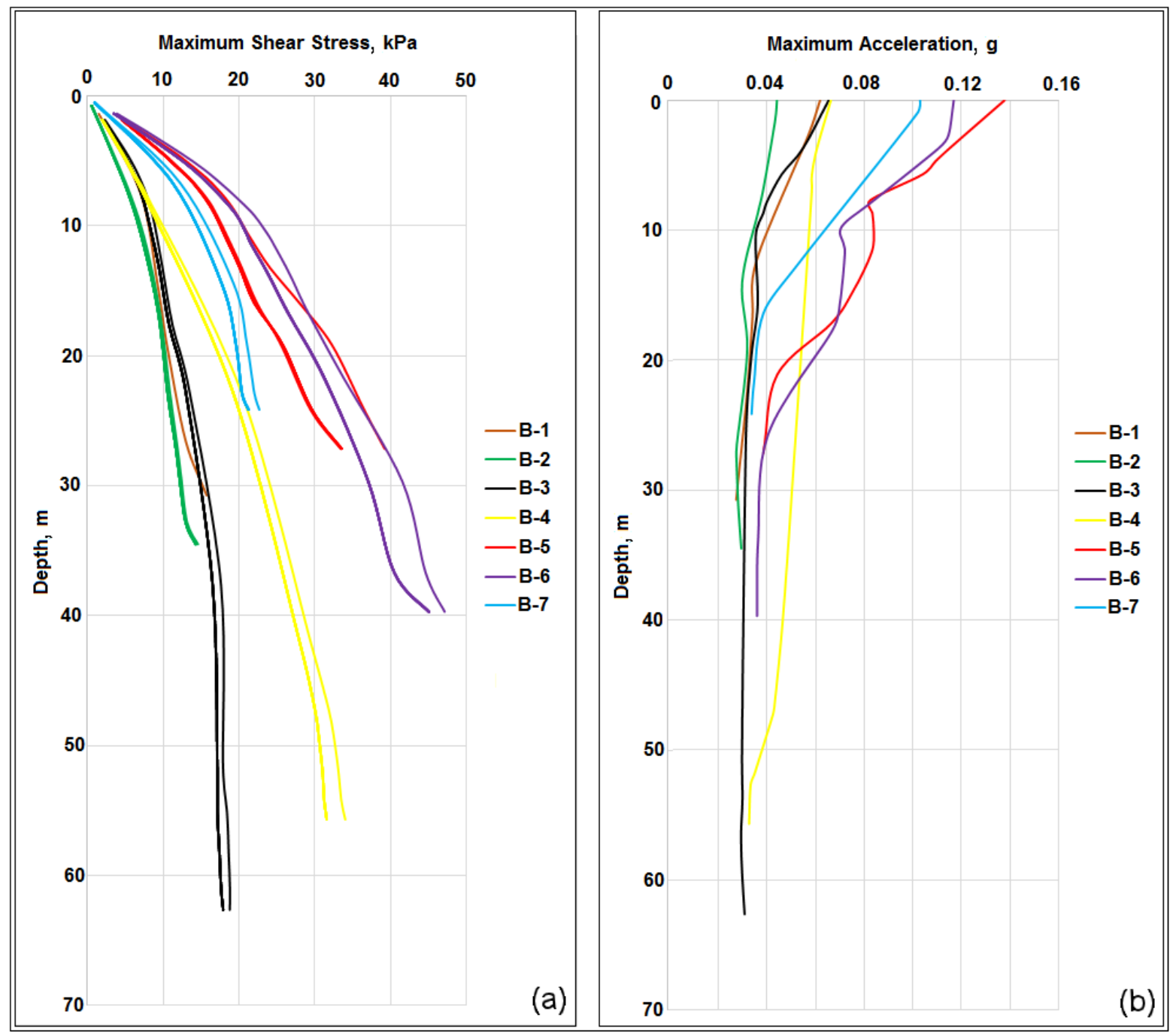

Figure 5. Comparative representation of shear stress and acceleration variations with depth of the boreholes from results of the 1D ground response analysis calculated with program, a) maximum shear stress $(\mathrm{kPa}), \mathrm{b})$ maximum acceleration $(\mathrm{g})$.

ters has been measured between 139-239 $\mathrm{MPa}$ in the borehole B-5. The same, the shear modulus for sheets deeper than 20 meters has been measured between 139-239 MPa in the borehole B-5. The shear modulus for sheets deeper than 18 meters has been measured between 159-201 MPa in the borehole B-1. Besides this the shear modulus for sheets deeper than 55 meters has been measured between 479-1299 $\mathrm{MPa}$ in the borehole B-4. The same, the shear modulus for sheets deeper than 33 meters has been measured between 49-6490 $\mathrm{MPa}$ in the borehole B-6. The shear modulus for sheets deeper than 21 meters has been measured between 399-1799 MPa in the borehole B-7 (Figure 6).
The amplitude ratios of acceleration values are seen to be different in the boreholes changing between 1.2 and 8.1. The amplitude ratios of the B-1, B-2 and B-3 are low. But it is high for the other boreholes with a ratio changing in the range 3.1 8.1 (Figure 8). Maximum amplifications and their frequency values have been given in Table 1 . It is seen that frequency of maximum amplifications for borehole B-3 is high $(7.4 \mathrm{~Hz})$ when it is lower for borehole B-4. As for maximum amplifications, it has relatively high (approximately 7.82) and low (approximately 1.22) values in boreholes B-5 and B-2, respectively. So maximum frequency was obtained in the borehole B-3 (Table 1). 


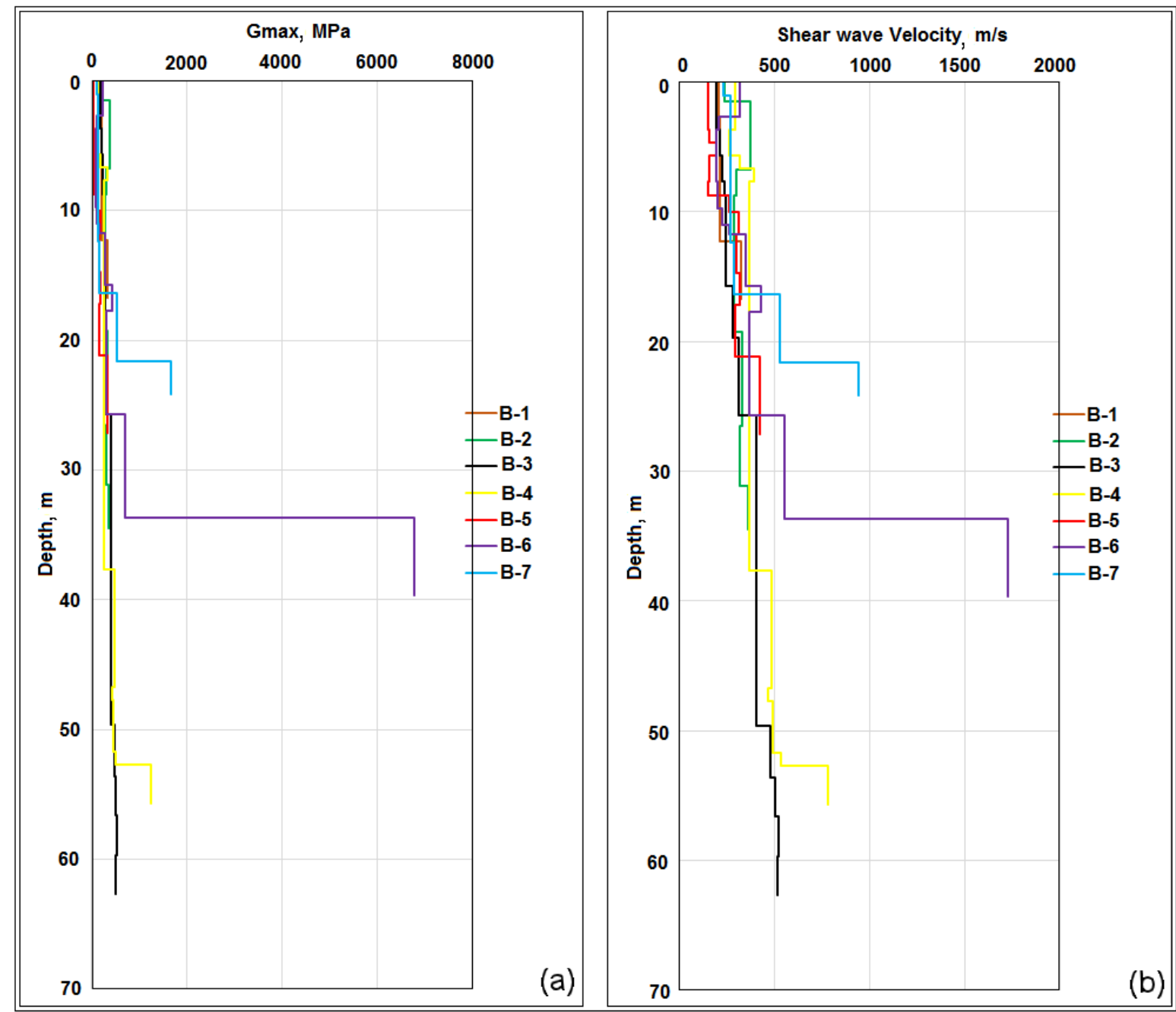

Figure 6. Comparative representation of $G_{\max }$ and shear stress variations with depth of the boreholes from results of the $1 \mathrm{D}$ ground response analysis calculated with program, a) $G_{\max }$-depth $(\mathrm{MPa})$ values, b) shear stress-depth $(\mathrm{m} / \mathrm{s})$ values.

The Fourier transform of the acceleration record demonstrates changes in amplitude at different frequencies. From borehole B-7 to the Bosphorus spectral accelerations rising, much likely due to the fact that the marine deposits acquiring thicker. Represents the variation of peak spectral acceleration values in the study area. Calculated surface spectral accelerations in the study area changes between 0.81 and $0.16 \mathrm{~g}$, are estimated that the boreholes used in the study penetrating through the marine deposits. Understandably from Table 2, the preponderance of B- 5 and B- 6 boreholes can be classified as being high value acceleration boreholes with respect to the others.

Table 1. Maximum Amplification and Frequency of Maximum Amplification ( $\mathrm{Hz})$ of Boreholes

\begin{tabular}{lccccccc}
\hline Boreholes & B-1 & B-2 & B-3 & B-4 & B-5 & B-6 & B-7 \\
\hline Maximum amplification & 1.58 & 1.23 & 1.73 & 2.87 & 7.83 & 6.05 & 5.16 \\
Frequency of maximum amplification $(\mathrm{Hz})$ & 2.8 & 2.4 & 7.4 & 2.0 & 2.6 & 2.8 & 3.8 \\
\hline
\end{tabular}




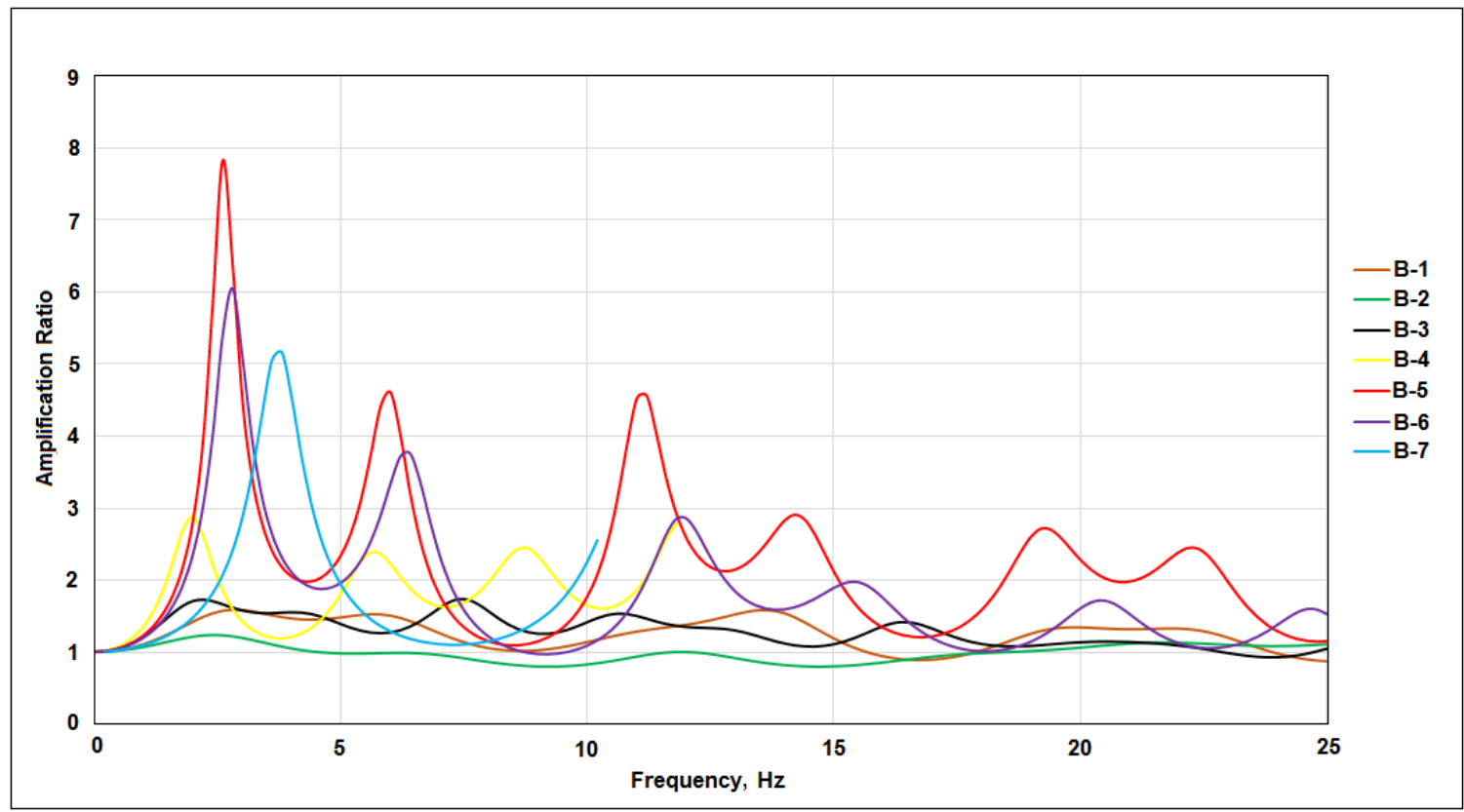

Figure 7. Comparative representation of spectral acceleration and period relationship of obtained from program study results.

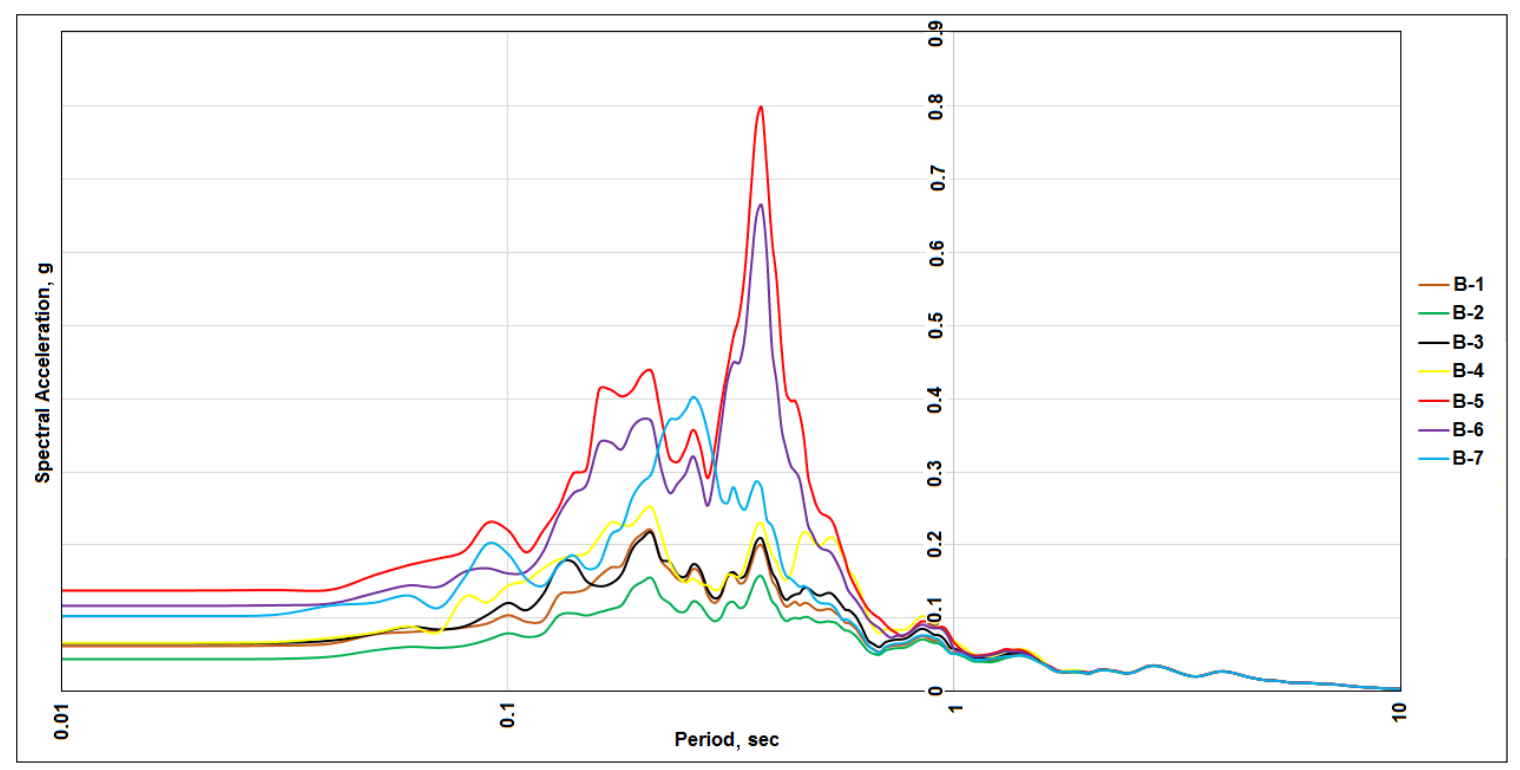

Figure 8. Comparative representation of amplitude ratio values of acceleration values of boreholes.

Table 2. Max Period (s) and Max Spectral Acceleration (g) of Boreholes

\begin{tabular}{lccccccr}
\hline Boreholes & B-1 & B-2 & B-3 & B-4 & B-5 & B-6 & B-7 \\
\hline Max period (s) & 0.21 & 0.36 & 0.21 & 0.21 & 0.37 & 0.37 & 0.23 \\
Max spectral acceleration (g) & 0.22 & 0.15 & 0.21 & 0.25 & 0.80 & 0.66 & 0.44
\end{tabular}


Table 3. The Calculated Maximum Values of Boreholes

\begin{tabular}{lccccc}
\hline \multicolumn{3}{c}{ Time Domain } & \multicolumn{2}{c}{ Frequency Domain } \\
\hline Boreholes & Acceleration & Displacement & $\begin{array}{c}\text { Particular } \\
\text { velocity }\end{array}$ & $\begin{array}{c}\text { Spectral } \\
\text { acceleration }\end{array}$ & $\begin{array}{c}\text { Dominant } \\
\text { period }\end{array}$ \\
\hline \multicolumn{3}{r}{ 17 August Kocaeli earthquake acceleration record of 0.04287 g was measured at the IBMPWS } \\
\hline B-1 & 0.062 & 0.031 & 0.002 & 0.22 & 0.21 \\
B-2 & 0.044 & 0.026 & 0.001 & 0.15 & 0.36 \\
B-3 & 0.065 & 0.037 & 0.003 & 0.25 & 0.21 \\
B-4 & 0.066 & 0.043 & 0.003 & 0.80 & 0.37 \\
B-5 & 0.138 & 0.073 & 0.004 & 0.66 & 0.37 \\
B-6 & 0.117 & 0.064 & 0.003 & 0.40 & 0.26 \\
B-7 & 0.103 & 0.038 & 0.001 & & \\
\hline
\end{tabular}

\section{Results}

In this study, the ground responses at the surface in different locations of İstanbul Metro line have been obtained using wave velocities, densities and thicknesses of the layers based on the PS logs from 7 borehole logs distant from each other with depth approximate $50 \mathrm{~m}$. The $\mathrm{E}-\mathrm{W}$ constituent parts of the acceleration record of the 17 August 1999 Kocaeli earthquake records at Beşiktaş earthquake station in İstanbul has been transferred to program. Thus, obtained response and design spectrums that are considered to be crucial during earthquake strong-ground motion.

Structural joints between the stations are important, but the İstanbul Metro tunnel has weak portions of the earthquake resistant design. Not only must they have superior anti-deformation properties, but they are also observed to forestall unacceptable deformation under seismic charge. Therefore, more attention should be gainful to seismic response analysis of the flexible joint partials.

There is a variation $290-300 \mathrm{~m} / \mathrm{s}$ velocity between top and down layers in the borehole B-5. The soils no homogeneous in this depth. The same, there has been seen a variation $\sim 695 \mathrm{~m} / \mathrm{s}$ velocity between top and down layers in the borehole B-6, in addition variation $1890 \mathrm{~m} / \mathrm{s}$ velocity in the borehole B-7. The spectrums similarity features of boreholes B-4, B-5, B-6 and B-7 is shown Figure 8. The boreholes B-5 and B-7 are located within the Trakya formation units and also fault zone. The maximum spectral acceleration values are higher according to others, because İstanbul Metro line is followed the fault zone in this region (Table 1). The basement rocks called Trakya formation units is not the followed in between boreholes B-1 and B-5, also followed as part of the sea from borehole B-5. Moreover, the slip surface of the old slide has been seen in between boreholes B-3 and B- 5 .

The maximum acceleration distribution along spectrum ratios and depth has been demonstrated that solutions of program analysis smaller peak acceleration. Also, linear site response analysis computes acceleration in small frequency range. For the solution of program, parameters should be chosen attentively to suitable for fluid, particle and porosity etc. specifications that define the material properties at various strain levels. In the joint connection locations of stations, the lower shear strengths values of project build have been shown in Figure 5 .

Dominant period has been increasing between 0.36-0.37 s in the B-2, boreholes B-5 and B-6, for this reason low frequency $\mathrm{S}$ wave in this area. The largest maximum acceleration has been measured in the borehole B-5. The lowest maximum acceleration has been measured in the borehole B-2. In order to an input acceleration value of $0.0426 \mathrm{~g}$ and maximum accelerations of the boreholes B-5, B-6 and B-7 in the time domain is obtained to be $0.138 \mathrm{~g}$ in borehole B-5, indicating amplifications in the order of ten folds. This situation is shown on the Table 3 . These boreholes are considered to be located inside of the fault zone.

Acknowledgments. The authors are also thankful to geotechnical engineer Sercan Öztürk and research assistant Mrs. Hilal Yalçın. 


\section{References}

Ansal, A., A. Akinci, G. Cultrera, M. Erdik, V. Pessina, G. Tönük, G. Ameri (2009), Loss estimation in Istanbul based on deterministic earthquake scenarios of the Marmara Sea region (Turkey), Soil Dynamics and Earthquake Engineering, 29, 699 709, Crossref

18

Bardet, J. P., K. Ichii, C. H. Lin (2000), EERA, A Computer Program for Equivalent Linear Earthquake Site Response Analysis of Layered Soils Deposits, University of Southern California, Los Angeles.

Beyhan, G., A. Keskinsezer, S. Öztürk (2016), Soil properties and applications review with NERA (nonlinear earthquake site response analyses) in İstanbulMARMARAY Project between Kazlçeşme to Sirkeci, Environmental Earth Sciences, January 2016, 7593, (http://link.springer.com/article/10.1007/s12665 -015-4783-y) Crossref

Biondi, G., M. R. Massimino, M. Maugeri (2014), Influence of frequency content and amplitude of input motion in DSSI investigated by shaking table tests, Bulletin of Earthquake Eng., 13, 1835-1869, Crossref

Campione, F., P. Capilleri, M. R. Massimino, M. Maugeri (2013), Terremoto dell'Emilia Romagna 2012: risposta sismica locale sulla base di prove SDMT, IARG 2013, 16-18 September 2013, Conference Paper IARG, Perugia.

(ISBN 9788890642135) Crossref

Erdik, M., M. Demircioğlu, K. Sesetyan, E. Durukal (2005), Assessment of earthquake hazard for Bakırköy, Gemlik, Bandırma, Tekirdăg and Körfez. WB MEER project-A3 component, microzonation and hazard vulnerability studies for disaster mitigation in pilot municipalities, Boğaziçi University, Kandilli Observatory and Earthquake Engineering Research Institute, Boğaziçi.

Huang, H. C., C. S. Shieh, H. C. Chiu (2001), Linear and nonlinear behaviors of soft soil layers using Lotung downhole array in Taiwan, Terr. Atmos. Ocean Sci., 12, 503-524, Crossref
Hwang, H. H. M., C. S. Lee (1991), Parametric study of site response analysis, Soil Dyn. Earthq. Eng., 10, No. 6, 282-290, Crossref

Joyner, W. B., A. T. F. Chen (1975), Calculation of nonlinear ground response in earthquakes, Bull. Seismol. Soc. Am., 65, 1315-1336.

Schnabel, P. B., J. Lysmer, H. B. Seed (1972), SHAKE: a computer program for earthquake response analysis of horizontally layered sites. Report No. EERC72-12, University of California, Berkeley.

Seed, H. B., I. M. Idriss (1970), Soil Moduli and Damping Factors for Dynamic Response Analysis. Report EERC 70-10, University of California, Earthquake Engineering Research Center, Berkeley.

Spence, R., et al. (2005), Technical report on the scenario earthquake defnitions for three cities. Deliverable 83, Project less loss on risk mitigation for earthquakes and landslides, Sub-Project 10 - earthquake disaster scenario predictions and loss modelling for urban areas. Sixth Framework Programmed, CORDIS, EU research results, European Commission, Brussels.

STFA (2005), Istanbul Metro. Final Geotechnical Factual Report. Taisei Corporation, STFA Temel Araştırma ve Sondaj, A.Ş.

Yoshida, N. (1994), Applicability of conventional computer code SHAKE to nonlinear problem, Proc. Symposium on Amplification of Ground Shaking in Soft Ground p. 14-31, JSSMFE, Japan. (in Japanese)

Yoshida, N., S. Iai (1998), Nonlinear site response analysis and its evaluation and prediction, 2nd International Symposium on the Effect of Surface Geology on Seismic Motion p. 71-90, Yokosuka, Japan.

\section{Corresponding author:}

Dr. Ayhan Keskinsezer (Ph.D.), Sakarya University, Engineering Faculty, Department of Geophysical Engineering, 54050 Serdivan-Sakarya, Turkey.

(ayhank@sakarya.edu.tr) 